\title{
Neonatal Hypoxia Triggers Transient Apoptosis Followed by Neurogenesis in the Rat CA1 Hippocampus
}

\author{
JEAN-LUC DAVAL, GRÉGORY POURIÉ, STÉPHANIE GROJEAN, VALÉRIE LIÈVRE, \\ CATHERINE STRAZIELLE, SÉBASTIEN BLAISE, AND PAUL VERT
}

INSERM EMI 0014, Faculté de Médecine, UHP, 54500 Vandoeuvre-lès-Nancy, France [J.-L.D., G.P., S.G., V.L., C.S., S.B.], and Médecine et Réanimation Néonatales, Maternité Régionale, 54000 Nancy, France [P.V.]

\begin{abstract}
ABST
Continuous generation of new neurons has been demonstrated
in the adult mammalian brain, and this process was shown to be
stimulated by various pathologic conditions, including cerebral
ischemia. Because brain oxygen deprivation is particularly fre-
quent in neonates and represents the primary event of asphyxia,
we analyzed long-term consequences of transient hypoxia in the
newborn rat. Within 24 h after birth, animals were exposed to
$100 \% \mathrm{~N}_{2}$ for 20 min at $36^{\circ} \mathrm{C}$, and temporal changes in the
vulnerable CA1 hippocampus were monitored. Cell density mea-
surements revealed delayed cell death in the pyramidal cell layer
reflecting apoptosis, as shown by characteristic nuclear morphol-
ogy and expression levels of Bcl-2, Bax, and caspase-3. Neuronal
loss was confirmed by reduced density of neuron-specific enolase
(NSE)-labeled cells, and peaked by 1 wk post insult, to reach
$27 \%$ of total cells. A gradual recovery then occurred, and no
significant difference in cell density could be detected between
controls and hypoxic rats at postnatal d 21 . Repeated injections
\end{abstract}
Transient reduction of oxygen supply to the brain is a common feature of the perinatal period, and remains a major cause of neurologic damage (1-3). Depending on the characteristics of the initial insult, consequences may vary from restricted neuronal loss to extensive brain infarction, reflecting the participation of an apoptotic-necrotic continuum (4-7). In this respect, hypoxic insults have been associated with delayed selective neuronal apoptosis that involves the active participation of specific gene products $(8-12)$.

The brain response to oxygen deprivation appears as a balance between the activation of neurodestructive components and endogenous protective mechanisms $(5,10)$. Among the various adaptative responses of the brain to severe injury, it has

Received May 28, 2003; accepted September 24, 2003.

Correspondence: Jean-Luc Daval, Ph.D., INSERM EMI 0014, Faculté de Médecine, 9 avenue de la Forêt de Haye, B.P. 184, 54505 Vandoeuvre-les-Nancy Cedex, France; e-mail: Jean-Luc.Daval@nancy.inserm.fr

Supported by INSERM.

DOI: 10.1203/01.PDR.0000113771.51317.37 of bromodeoxyuridine $(50 \mathrm{mg} / \mathrm{kg})$ showed that newly divided cells expressing neuronal markers increased by $225 \%$ in the germinative subventricular zone, and they tended to migrate along the posterior periventricle toward the hippocampus. Therefore, transient hypoxia in the newborn rat triggered apoptosis in the CA1 hippocampus followed by increased neurogenesis and apparent anatomical recovery, suggesting that the developing brain may have a high capacity for self-repair. (Pediatr Res 55: 561-567, 2004)
BrdU, bromodeoxyuridine
CO, cytochrome oxidase
DAPI, 4,6-diamidino-2-phenylindole
DG, dentate gyrus
NSE, neuron-specific enolase
SVZ, subventricular zone

been recently reported that new neurons can be generated through the proliferation of progenitor cells, and thus might help to repair the damaged CNS $(13,14)$. Several studies have documented that experimental ischemia in the adult brain can trigger neurogenesis as a compensatory mechanism to neural cell death (15-19). Indeed, it is now clearly established that continuous generation of new neurons occurs in the adult mammalian brain $(20,21)$. Newborn cells originate from specific germinative zones, namely the SVZ surrounding the lateral ventricle, and the subgranular cell layer of DG in the hippocampus $(22,23)$, although neurogenesis has been reported in other regions, e.g. the cerebral cortex and the spinal cord $(24,25)$.

The developing brain displays specific sensitivity to oxygen supply $(26,27)$, and its capacities of plasticity and remodeling are particularly high. By studying the effects of pure hypoxic conditions on the fetal and postnatal rat brains by transient exposure to hypoxia of mother rats during late gestation, Li et al. (28) observed a significant cell degeneration in various 
brain areas of the rat pups, but neuron density was then found to be restored to normal levels by $1 \mathrm{wk}$ after hypoxia. We therefore tested the hypothesis that exposure to transient neonatal hypoxia may secondarily induce neurogenesis in the rat brain. For this purpose, rat pups were exposed to a 20 -min episode of oxygen deprivation within $24 \mathrm{~h}$ after birth, a treatment thought to mimic birth asphyxia $(29,30)$. The temporal effects of hypoxia were characterized in the CA1 hippocampus, a brain region known to be exquisitely sensitive to oxygen delivery (31), and potential neurogenesis was monitored by the DNA incorporation of the thymidine analogue, BrdU.

\section{METHODS}

Induction of hypoxia. Animal experiments were carried out with the highest standards of animal care and housing, according to the NIH Guide for the Care and Use of Laboratory Animals. Pregnant female Sprague-Dawley rats (R. Janvier, Le Genest-St-Isle, France) were constantly maintained under standard laboratory conditions on a 12-h light/dark cycle (lights on at $0600 \mathrm{~h}$ ), with food and water available ad libitum.

Between 8 and $24 \mathrm{~h}$ after delivery, half of the neonates were placed for $20 \mathrm{~min}$ in a thermostated Plexiglas chamber flushed with $100 \% \mathrm{~N}_{2}$, whereas the remaining pups were taken as matched controls and exposed to $21 \% \mathrm{O}_{2} / 79 \% \mathrm{~N}_{2}$ (i.e. oxygen concentration corresponding to normal atmosphere) for the same time. The temperature inside the chamber was adjusted to $36^{\circ} \mathrm{C}$ to maintain body temperature in the physiologic range. All pups were allowed to recover for $20 \mathrm{~min}$ in normoxic conditions, and they were then returned to their dams. In such experimental conditions, the overall mortality was $4 \%$ in hypoxic rats, and the litter size was finally reduced to 10 pups, corresponding to 5 controls and 5 hypoxic rats, for homogeneity in subsequent experiments. Animals were killed by decapitation at various time intervals posttreatment, i.e. at $\mathrm{d} 1,2$, $3,4,5,6,7,13,20,40$, or 60 after exposure to gas for histopathological studies and monitoring of apoptosis, at d 3, 6, 13 , or 20 for protein immunohistochemistry and measurements of $\mathrm{CO}$ activity, and at d 20 for BrdU labeling studies. Their brains were rapidly collected and immediately frozen in methylbutane previously chilled to $-30^{\circ} \mathrm{C}$. Subsequently, they were coated with embedding medium (4\% carboxymethylcellulose in water), and cut at $-20^{\circ} \mathrm{C}$ in a cryostat (Frigocut 2800 , Reichert-Jung, Les Ulis, France) to generate $20-\mu \mathrm{m}$ sagittal sections, starting from the sagittal zero plane that bisects the brain mid-sagittally, as defined in the developing rat brain atlas of Sherwood and Timiras (32). Tissue sections were finally mounted onto glass slides, and stored at $-80^{\circ} \mathrm{C}$ for further analyses.

Histopathological studies. Cell density was measured in the CA1 pyramidal cell layer of the hippocampus by incubating brain sections for $10 \mathrm{~min}$ in PBS containing the nuclear fluorescent dye 4,6-diamidino-2-phenylindole (DAPI, $0.5 \mu \mathrm{g} /$ $\mathrm{mL}$, Sigma Chemical, St. Louis, MO, U.S.A.), according to Wolvetang et al. (33). The number of cell nuclei selectively labeled by DAPI was scored at $365 \mathrm{~nm}$ under fluorescence microscopy (Axioscop, Zeiss, Strasbourg, France). Cell density was assessed at a $40 \times$ magnification in at least three separate experiments by counting cells in three distinct section areas delineated by an ocular grid of $1 / 400 \mathrm{~mm}^{2}$. For each selected field, only cells with their nuclei present in the focal plane were counted. Numbers of cells were finally calculated per square millimeter.

Monitoring of apoptosis. Morphologic hallmarks of apoptosis were visualized in tissue sections after nuclear staining by DAPI, as previously documented (34-36). Indeed, it has been demonstrated that healthy DAPI-labeled cells exhibit intact round-shaped nuclei with diffuse fluorescence. Necrotic cells are characterized by highly refringent smaller nuclei with uniformly dispersed chromatin, whereas apoptosis is associated with condensation and fragmentation of chromatin, leading to typically shrunken nuclei and apoptotic bodies. Characteristic nuclei were scored under fluorescence microscopy in five separate experiments with counts performed in at least three distinct areas of 100 cells.

In addition, regional expressions of three prototypic proteins involved in the regulation of brain apoptosis, i.e. Bax and capase-3 as pro-apoptotic proteins as well as Bcl-2 as an anti-apoptotic protein, were monitored. For this purpose, previously fixed brain sections were incubated at $4^{\circ} \mathrm{C}$ for $48 \mathrm{~h}$ with a rabbit polyclonal antibody against Bax $(1 / 20$, Santa Cruz Biotechnology, Santa Cruz, CA, U.S.A.), a goat polyclonal antibody against the active p20 subunit of caspase-3 (CPP32 p20, 1/40, Santa Cruz Biotechnology), or a goat polyclonal antibody against Bcl-2 (1/30, Santa Cruz Biotechnology). Revelation was performed after washing steps by a 120 -min incubation in the presence of the corresponding secondary antibody, namely anti-rabbit IgG conjugated to indocarbocyanine (Cy3, dilution 1/100, Jackson ImmunoResearch, West Grove, PA) or anti-goat IgG conjugated to FITC (dilution 1/100, Jackson ImmunoResearch). Slides were then washed three times in PBS, coverslipped using mounting medium (Aquapolymount, Polysciences, Warrington, PA, U.S.A.), and kept in the dark until fluorescence analysis.

In an attempt to quantify the level of protein expression, cell fluorescence activity was computerized from microphotographs, and mean intensity was calculated by using Adobe Photoshop (version 5.0), and expressed as arbitrary units of mean emission per 1000 pixels, as previously described (10, 37).

CO histochemistry. Because brain adaptation in response to transient hypoxia may be related, at least partly, to metabolic changes, overall neuronal metabolic activity was evaluated in the CA1 hippocampal pyramidal cell layer by the measurement of CO activity as originally described by Wong-Riley (38) and slightly modified by Strazielle et al. (39). At representative time points after gas exposure (d 3, 6, 13, and 20), brain tissue sections were incubated in the dark for $75 \mathrm{~min}$ at $37^{\circ} \mathrm{C}$ in a continuously stirred solution of $0.1 \mathrm{M}$ PBS (pH 7.4) containing $0.55 \mathrm{mg} / \mathrm{mL}$ 3,3'-diaminobenzidine tetrachloride (DAB, Sigma Chemical), $0.22 \mathrm{mg} / \mathrm{mL}$ horse-heart cytochrome $c$ (Sigma Chemical), $0.2 \mathrm{mg} / \mathrm{mL}$ catalase (Sigma Chemical), and 44.5 $\mathrm{mg} / \mathrm{mL}$ sucrose. Slides were washed in ice-cold buffer and immersed in a $10 \%$ buffered formalin solution for $30 \mathrm{~min}$. They were then washed for $5 \mathrm{~min}$ in buffer at room temperature, dehydrated in successive ethanol and xylene baths, and cover- 
slipped with mounting medium. Brain sections from hypoxic and matched control rats were processed in parallel. Experiments were validated by the absence of $\mathrm{CO}$ reaction product when DAB was omitted or in the additional presence of $0.01 \mathrm{M}$ potassium cyanide.

Enzyme activity was quantified by densitometric analysis by means of a computerized image-processing system (Biocom, Les Ulis, France), and by using freshly prepared calibrated standards (40) to convert OD into enzymatic activity as micromoles per minute per milligram of proteins.

Labeling of proliferating cells, and phenotype characterization. BrdU (Sigma Chemical), which incorporates into newly synthesized DNA, was used to label proliferating cells in rats of both control and hypoxia groups. BrdU was solubilized in $0.9 \% \mathrm{NaCl}$ containing $0.007 \mathrm{~N} \mathrm{NaOH}$, and given intraperitoneally at the dose of $50 \mathrm{mg} / \mathrm{kg}$ either as a single injection the day before the sacrifice for counting the number of replicating cells or once a day between d 11 and 19 posthypoxia for cell phenotype studies, according to Liu et al. (15). At $21 \mathrm{~d}$, rats were killed by decapitation, and their brains rapidly removed and frozen in methylbutane to be subsequently sectioned.

For BrdU immunostaining, DNA was first denatured by incubating sagittal brain sections in $2 \mathrm{~N} \mathrm{HCl}$ for $45 \mathrm{~min}$ at room temperature followed by a $10 \mathrm{~min}$ wash in $0.1 \mathrm{M}$ sodium borate at $\mathrm{pH}$ 8.5. Tissue was rinsed in PBS for $10 \mathrm{~min}$, then blocked in PBS containing 10\% goat serum for $1 \mathrm{~h}$, and was incubated overnight at $4^{\circ} \mathrm{C}$ with a mouse MAb against $\mathrm{BrdU}$ diluted at 1/100 (Oncogene Research Products, Boston, MA, U.S.A.). Incorporated BrdU was finally revealed by incubating brain slices for $1 \mathrm{~h}$ at room temperature in the presence of a rhodamine-conjugated secondary antibody (1/100, Sigma Chemical).

To count BrdU-positive cells, 12 sections collected every $400 \mu \mathrm{m}$ starting from the appearance of the hippocampus were used for each rat brain. Labeled nuclei were scored in areas of the SVZ delineated by an ocular grid of $1 / 400 \mathrm{~mm}^{2}$, and their number was calculated per square millimeter.

To identify the phenotype of newly generated cells at $20 \mathrm{~d}$ posthypoxia, tissue sections were processed for immunologic detection of NSE (a neuronal marker), neuro D (also designated BETA 2, a marker of immature, differentiating neurons), and glial fibrillary acid protein (GFAP, a marker for astrocytes). The experimental protocol was as described above, and a rabbit polyclonal antibody against NSE (dilution 1/100, Chemicon International, Temecula, CA, U.S.A), a goat polyclonal antibody against Neuro D (dilution $1 / 100$, Santa Cruz Biotechnology), and a mouse MAb against GFAP (1/200, Chemicon International) were used, respectively, with their corresponding second-step antibodies (anti-rabbit IgG, antigoat $\operatorname{IgG}$, or anti-mouse $\operatorname{IgG}$ conjugated to either Cy3 or FITC, all diluted at $1 / 100$ and obtained from Jackson ImmunoResearch).

Statiscal analyses. Raw data were obtained from at least three independent experiments using two to five rat pups of each experimental group, and all were normally distributed. Statistical analyses were performed following ANOVA. Results were finally compared by using Dunnett's test for multi- ple comparisons, and differences between hypoxic rats and normoxic controls were considered significant for $p<0.05$.

\section{RESULTS}

$\boldsymbol{C A}_{\boldsymbol{1}}$ histologic changes. Neonatal hypoxia progressively elicited a reduction of cell density in the CA1 pyramidal cell layer of the rat hippocampus (Fig. 1). As shown by DAPI labeling of cell nuclei and subsequent counts, the total number of cells was significantly decreased starting from $3 \mathrm{~d}$ posthypoxia compared with controls, and cell loss increased as a function of time to reach a maximum corresponding to $27 \%$ of total cells at $6 \mathrm{~d}$ after the insult. However, a gradual histologic recovery was then recorded, and hippocampal cell density was definitely not significantly different from controls by $20 \mathrm{~d}$ after birth hypoxia (Fig. 1).

Quantification of characteristic morphologically altered cell nuclei revealed an ongoing apoptotic process that culminated at 6-7 d posthypoxia, in good correlation with the evolution of cell density (Fig. 2, top ). Apoptosis was confirmed by the progressive overexpression of proteins specifically involved in brain apoptotic cell death, such as Bax and caspase-3. In parallel, expression of the survival effector Bcl-2 was first augmented and then decreased (Fig. 2, bottom). Maximal changes in protein expressions were measured at $6 \mathrm{~d}$ posthypoxia, concomitant to the peak of cell death. Thereafter, the apparent anatomical restoration was accompanied by a reversal of the protein expression profile, along with a reduction of the number of apoptotic nuclei that finally reached control values (Fig. 2).

Metabolic cell activity. In response to acute hypoxia, $\mathrm{CO}$ activity was significantly but transiently altered in the CA1 pyramidal cell layer of rats (Fig. 3). At 6 and $13 \mathrm{~d}$ post insult, the enzyme activity increased by $50 \%$ and $28 \%$, respectively, whereas CO activity was similar to control values at $20 \mathrm{~d}$.

Cell proliferation. Figure 4 illustrates the cell recovery observed at the level of the CA1 pyramidal cell layer by $20 \mathrm{~d}$ after exposure to hypoxia compared with cell damage recorded at $6 \mathrm{~d}$ post insult. It clearly appears that hypoxia-induced cell

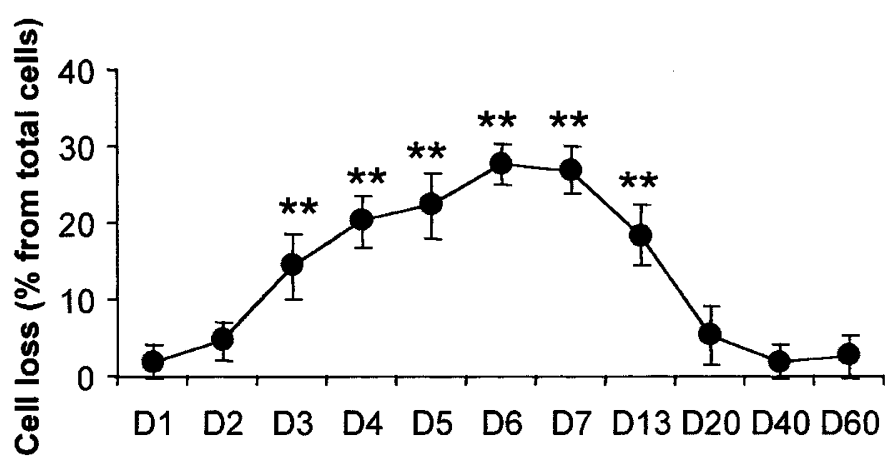

Figure 1. Evolution of cell loss in the rat CA1 hippocampus after neonatal hypoxia. After nuclear staining by DAPI, cell density (per $\mathrm{mm}^{2}$ ) was measured at various time intervals in the CA1 pyramidal cell layer in both control and hypoxic rats, and hypoxia-associated cell loss was calculated by comparison with matched controls. Data are means \pm SD and were obtained from three separate experiments, each using two control and two hypoxic rats per time point. Statistically significant differences from controls: $* * p<0.01$ (ANOVA followed by Dunnett's test for multiple comparisons). $\mathrm{D}=$ day postexposure. 

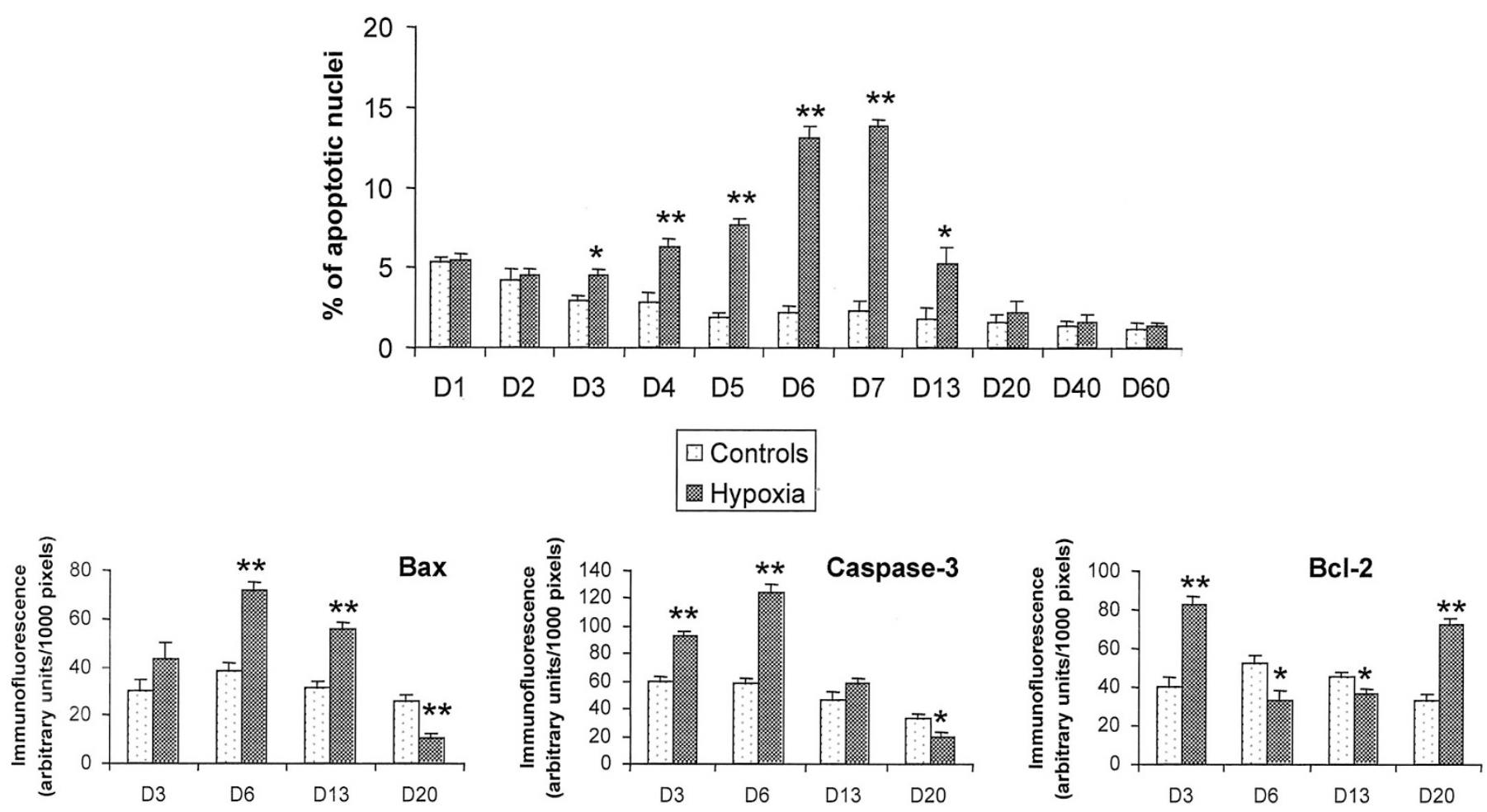

Figure 2. Evolution of apoptosis-related features in the rat CA1 hippocampus after neonatal hypoxia (D = day postexposure). (Top) Temporal profile of morphologic hallmarks of nuclear apoptosis (DAPI labeling) in hypoxic rats and matched controls. Data are reported as percentages of total cells (means \pm SD), and were obtained from five separate experiments, each using two control and two hypoxic rats per time point. Statistically significant differences from controls: ${ }^{* *} p<0.01$ (ANOVA followed by Dunnett's test for multiple comparisons). (Bottom) Expression patterns of prototypic neuronal apoptosis-regulating proteins. At representative time points after exposure to hypoxia, expression levels of Bax, caspase-3 (pro-apoptotic proteins), and Bcl-2 (anti-apoptotic protein) were analyzed by immunohistochemistry in brain sections of hypoxic rats and matched controls. For each sample section, cell fluorescence was calculated as arbitrary units per 1000 pixels. The data are means \pm SD obtained from four separate experiments, each using two control and two hypoxic rats per time point. Statistically significant differences from controls: ${ }^{*} p<0.05$ and ${ }^{* *} p<0.01$ (ANOVA followed by Dunnett's test for multiple comparisons).

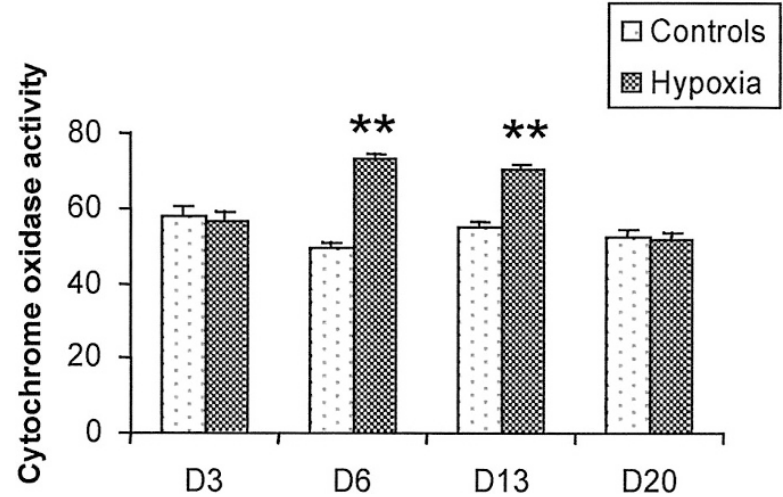

Figure 3. $\mathrm{CO}$ activity in the CA1 hippocampus of hypoxic rats and matched controls. CO regional histochemistry was performed in brain sections at various time points after exposure, and enzymatic activity was calculated as micromole per minute per milligram of protein. Data are means $\pm \mathrm{SD}$, and were obtained from four separate experiments, each using two control and two hypoxic rats per time point. Statistically significant differences from controls: ${ }^{* *} p<0.01$ (ANOVA followed by Dunnett's test for multiple comparisons). D $=$ day postexposure

injury present at $6 \mathrm{~d}$ mainly concerned neurons, as shown by the loss of NSE-labeled cells. Subsequently, the parallel increases of DAPI and NSE staining at $20 \mathrm{~d}$ suggest that neurons are able to be gradually regenerated. Within the SVZ lying along the ependymal layer of lateral ventricle, the number of BrdU-positive cells in hypoxic rat brains was not different from controls at $12 \mathrm{~d}$ posthypoxia $(204 \pm 105$ versus $142 \pm 32$ cells $/ \mathrm{mm}^{2}$ ). By contrast, it increased sharply by $20 \mathrm{~d}$ posthypoxia, from $149 \pm 78$ cells $/ \mathrm{mm}^{2}$ in controls to $485 \pm 59$ cells $/ \mathrm{mm}^{2}$ in hypoxic brain sections ( $p<0.01, n=6$ animals).

As shown on Figure 5, BrdU immunofluorescence was essentially distributed in the SVZ as well as along the posterior periventricle (PPV), where labeled cells formed a migrating chain toward the periventricular region located above the hippocampus. Multiple-labeling experiments showed that, whereas DAPI staining was also concentrated in the same brain areas, newborn cells labeled by BrdU expressed molecular markers for either mature (NSE) or differentiating neurons (Neuro D). Although not shown, none of the BrdU-positive cells expressed the glial marker GFAP. Also, BrdU labeling could not be noticeably detected within the CA1 hippocampal cell layers themselves or in the DG.

\section{DISCUSSION}

Due to the lack of consensus on a reliable and predictable experimental model to study the effects of perinatal asphyxia, we attempted in the present experiments to evaluate the brain consequences of hypoxia as a primary event of asphyxia in the newborn rat. According to our knowledge of the maturation rates of human and rat central nervous systems $(41,42)$, and especially of their hippocampal formations $(43,44)$, the rat is 


\section{DAYS POST-HYPOXIA}

DAPI
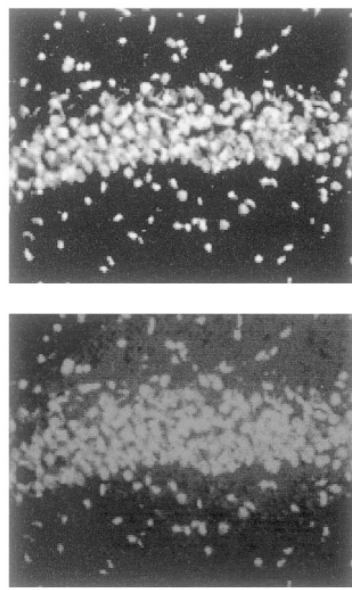

NSE
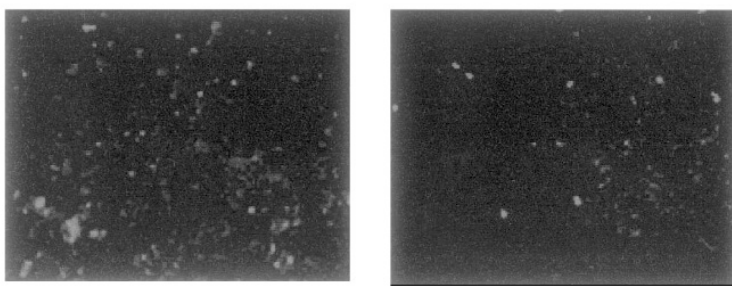

Figure 4. Cell density and corresponding expression of neuronal (NSE) and astrocytic (GFAP) cell markers in the CA1 hippocampus of rats at 6 and $20 \mathrm{~d}$ after exposure to neonatal hypoxia. At each time point, double labeling by DAPI and NSE as well as DAPI and GFAP was performed on adjacent brain sections. Note the higher cell density and associated NSE labeling at $20 \mathrm{~d}$ compared with $6 \mathrm{~d}$ postexposure $(40 \times$ magnification). Similar profiles were observed in three separate experiments.

born prematurely compared with the human. Therefore, our observations collectively might apply more specifically to the rather immature brain.

In good agreement with previous studies performed both in vivo and in vitro (8-12), transient exposure to oxygen deprivation around birth induced delayed cell death in the CA1 pyramidal layer of the hippocampus in rat pups. Cell degeneration was shown to exhibit the characteristic hallmarks of apoptosis, including chromatin condensation, clumping, and fragmentation into spheric apoptotic bodies, as well as changes in the expression levels of proteins specifically involved in the regulation of the apoptotic cascade (45-47). Time course studies indicated that the extent of cell loss and apoptotic features reached a maximum around $1 \mathrm{wk}$ after hypoxia, and immunohistochemical analyses confirmed that most of the injured cells corresponded to neurons. Thereafter, a gradual anatomical recovery could be repeatedly observed, and cell counts in the hippocampal CA1 sector were definitely comparable to controls by $20 \mathrm{~d}$ posthypoxia. Whereas the period of cell degeneration was associated with the expression of proteins in favor of apoptosis, like Bax and caspase-3, a shift in protein abundance in favor of the anti-apoptotic protein $\mathrm{Bcl}-2$ was recorded at $20 \mathrm{~d}$ posthypoxia. Such a process may account, at least partly, for the concomitant recovery, and it is noteworthy that increased expression of $\mathrm{Bcl}-2$ has been implicated in
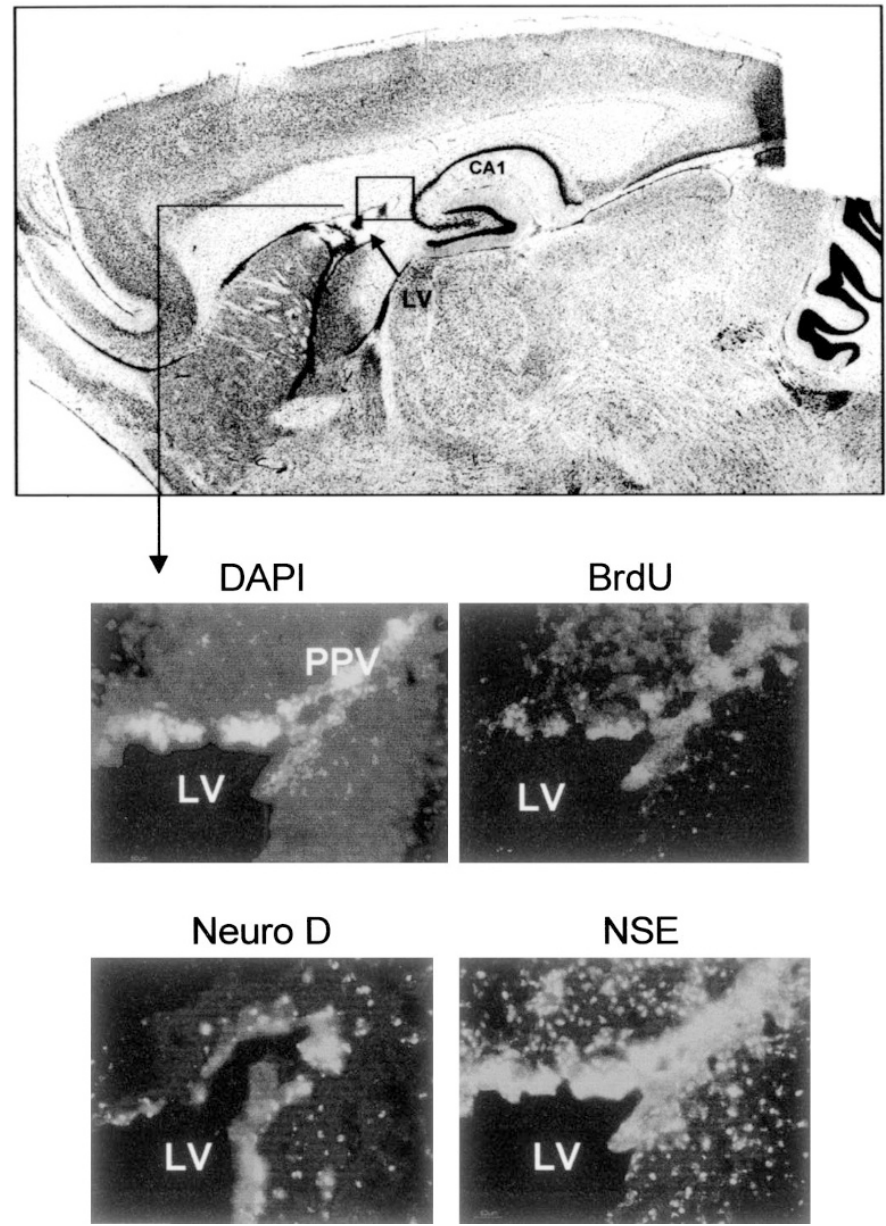

Figure 5. Characterization of cell proliferation in the rat SVZ at $20 \mathrm{~d}$ after exposure to neonatal hypoxia. Rats $(n=4)$ received a daily injection of BrdU $(50 \mathrm{mg} / \mathrm{kg}$ ) for $9 \mathrm{~d}$ before sacrifice. Multiple-labeling experiments performed on sagittal brain sections revealed that BrdU-positive cells were concentrated within the SVZ and along the posterior periventricle (PPV). The hypoxiaassociated proliferating cells expressed markers for either mature (NSE) or differentiating (Neuro D) neurons. Experiments were repeated four times with similar observations.

the survival and differentiation of newborn neurons issued from the SVZ (48).

Activity of $\mathrm{CO}$, the terminal enzyme complex of the electron transfer chain in mitochondria, has been shown to be specifically related to neuronal metabolic activity $(49,50)$. By contrast to the radioactive 2-deoxyglucose method described by Sokoloff et al. (51), the histochemical determination of CO activity allows the measurement of a steady-state functional activity at the cellular level in a specific brain area. In our model, $\mathrm{CO}$ activity in the CA1 hippocampus was more elevated at 6 and $13 \mathrm{~d}$ posthypoxia than in controls, and was then restored to normal levels by $20 \mathrm{~d}$ post insult. Several authors have reported reduced $\mathrm{CO}$ activities within a few hours after cerebral ischemia (52-54). This may reflect severe, irreversible brain injury. In the present study, neonatal hypoxia that allows progressive recovery may induce a redistribution of brain energy metabolism facilitating long-term survival. In this respect, it has been proposed that impaired energy metabolism would indirectly lead to persistent overstimulation of $\mathrm{N}$ - 
methyl-D-aspartate receptors, resulting in greater excitoxic neurodegeneration (55). Therefore, the recorded increase in $\mathrm{CO}$ activity may serve to slow the degenerative process. This is supported by the report that ischemic preconditioning may prevent global ischemia-associated brain damage by preserving mitochondrial oxidative functions (56).

Of particular interest is the obvious anatomical restoration of the CA1 hippocampus after neonatal hypoxia. Histologic analyses suggest that neuronal degeneration depicted after hypoxia in the CA1 subfield of the rat pup is then followed by an increase in cell density, possibly reflecting compensatory formation of new neurons. These findings are consistent with recent studies reporting enhanced neurogenesis in the adult brain of various species by several days or weeks after ischemic insults (15-19). Most of these studies, however, have focused on cellular events in another documented neurogenic site of the brain - the subgranular zone of the DG. An ischemia-associated increase of cell proliferation was usually described in this latter area, followed by the migration of newborn neurons to the granule cell layer of the DG. According to Liu et al. (15), this phenomenon is not correlated with neuronal loss in the CA1 pyramidal cell layer. Although the DG was not specifically investigated in the present study, no patent changes could be seen after hypoxia.

The SVZ lying along the ependymal layer of the lateral ventricle is known to generate neural progenitor cells throughout postnatal life destined to specific areas of the mammalian brain (57), and our data suggest that neurogenesis in this cerebral region might be a critical element in brain repair after hypoxia. Administrations of the thymidine analogue BrdU showed a substantial increase (225\%) in the number of cells expressing neuronal markers within the SVZ of 21-d-old rats exposed to neonatal hypoxia. Although BrdU may potentially indicate DNA repair (58), the long delay existing between the hypoxic insult and BrdU injection, the dose of BrdU administered, the marked augmentation of its incorporation rate recorded in the SVZ - which harbors numerous progenitor cells - as well as the absence of BrdU-positive cells in the injured CA1 layer strongly suggest that BrdU labeling actually reflects proliferating cells. Our findings seem at first to contrast with those of Levison et al. (59), who reported that hypoxiaischemia depletes the rat perinatal SVZ of neural stem cells. However, the same authors recently showed the recruitment of such neural stem cells after perinatal ischemic insult, and they concluded that some regional specificity may exist within the SVZ in response to hypoxia-ischemia (60).

Under physiologic conditions, neurons originating from the SVZ of the postnatal rodent brain have been shown to migrate along the rostral migratory stream, a restricted pathway toward the olfactory bulb where they ultimately differentiate into granule and periglomerular cell interneurons $(61,62)$. After neonatal hypoxia, we have observed a high concentration of BrdU-positive cells in the posterior periventricle, and it is tempting to speculate that at least some of these proliferating cells that express neuronal markers may migrate from the periventricular zone to the hippocampal CA1 region, where they would contribute to replenish the damaged pyramidal cell layer. Consistent with our study, Schmidt and Reymann (63) recently provided evidence for the appearance of newly born cells expressing the neuronal marker NeuN, but not the glial marker GFAP, in the degenerated CA1 pyramidal cell layer 4 wk after global brain ischemia in gerbils. Also, it has been reported that transient middle cerebral artery occlusion in the adult rat can stimulate cell proliferation in the SVZ to generate neurons that finally migrate to the severely damaged area of the striatum (64).

Taken together, the above data suggest that the developing brain possesses a capacity for regionally targeted self-repair. Nonetheless, it is known that even mild neonatal asphyxia may induce long-term functional disabilities, including poorer learning performances (1-3), and this poses the important question of whether new neurons are able to restore-or at least improve- hippocampal activity. During the course of our own study, Nakatomi and colleagues (65) elegantly demonstrated that after transient forebrain ischemia in the adult rat, endogenous progenitors can proliferate and migrate to the CA1 hippocampus to regenerate injured pyramidal neurons. Importantly, their data strongly suggest that these regenerated neurons were integrated into the existing hippocampal circuitry and contributed to ameliorating neurologic deficits. Also, van Praag et al. (66) convincingly showed that newly generated cells in the adult mouse brain gives rise to functional neurons in the hippocampus.

To date, neurogenic signals as well as specific mechanisms involved in the generation of new neurons after brain injury are still unknown. Numerous candidate components have been suggested to participate to the cellular and molecular pathways controlling proliferation, differentiation, migration, and survival of neural precursor populations $(19,20,67)$, and a better identification of their exact contributions should help to develop new therapeutic strategies.

Acknowledgment. The authors thank B. Foliguet (Laboratoire de Microscopie Electronique, Faculté de Médecine, Nancy) for his help and free access to image processing system facilities.

\section{REFERENCES}

1. Patel J, Edwards AD 1997 Prediction of outcome after perinatal asphyxia. Curr Opin Pediatr 9:128-132

2. Berger R, Garnier Y 1999 Pathophysiology of perinatal brain damage. Brain Res Brain Res Rev 30:107-134

3. Maneru C, Junque C, Botet F, Tallada M, Guardia J 2001 Neuropsychological long-term sequelae of perinatal asphyxia. Brain Inj 15:1029-1039

4. Haddad GG, Jiang C $1993 \mathrm{O}_{2}$ deprivation in the central nervous system: on mechanisms of neuronal response, differential sensitivity and injury. Prog Neurobiol 40:277-318

5. Walton M, Connor B, Lawlor P, Young D, Sirimanne E, Gluckman P, Cole G, Dragunow M 1999 Neuronal death and survival in two models of hypoxic-ischemic brain damage. Brain Res Brain Res Rev 29:137-168

6. Nakajima W, Ishida A, Lange MS, Gabrielson KL, Wilson MA, Martin LJ, Blue ME, Johnston MV 2000 Apoptosis has a prolonged role in the degeneration after hypoxic ischemia in the newborn rat. J Neurosci 20:7994-8004

7. Benchoua A, Guégan C, Couriaud C, Hosseini H, Sampaïo N, Morin D, Onténiente B 2001 Specific caspase pathways are activated in the two stages of cerebral infarction. J Neurosci 21:7127-7134

8. Banasiak KJ, Haddad GG 1998 Hypoxia-induced apoptosis: effect of hypoxic severity and roles of p53 in neuronal cell death. Brain Res 797:295-304

9. Bossenmeyer C, Chihab R, Muller S, Schroeder H, Daval JL 1998 Hypoxia/ reoxygenation induces apoptosis through biphasic induction of protein synthesis in central neurons. Brain Res 787:107-116

10. Bossenmeyer-Pourié C, Lièvre V, Grojean S, Koziel V, Pillot T, Daval JL 2002 Sequential expression patterns of apoptosis- and cell cycle-related proteins in neuronal response to severe or mild transient hypoxia. Neuroscience 114:869-882 
11. Tamatani M, Ogawa S, Tohyama M 1998 Roles of Bcl-2 and caspases in hypoxiainduced neuronal cell death: a possible neuroprotective mechanism of peptide growth factors. Brain Res Mol Brain Res 58:27-39

12. Tamatani M, Mitsuda N, Matsuzaki H, Okado H, Miyake SI, Vitek MP, Yamaguchi A, Tohyama M 2000 A pathway of neuronal apoptosis induced by hypoxia/ reoxygenation: roles of nuclear factor- $\kappa \mathrm{B}$ and Bcl-2. J Neurochem 75:683-693

13. Gould E, Tanapat P 1997 Lesion-induced proliferation of neuronal progenitors in the dentate gyrus of the adult rat. Neuroscience 80:427-436

14. Parent JM, Valentin VV, Lowenstein DH 2002 Prolonged seizures increase proliferating neuroblasts in the adult rat subventricular zone-olfactory bulb pathway. J Neurosci 22:3174-3188

15. Liu J, Solway K, Messing RO, Sharp FR 1998 Increased neurogenesis in the dentate gyrus after transient global ischemia in gerbils. J Neurosci 18:7768-7778

16. Jiang W, Gu W, Brännström T, Rosqvist R, Wester P 2001 Cortical neurogenesis in adult rats after transient middle cerebral artery occlusion. Stroke 32:1201-1207

17. Kee NJ, Preston E, Wojtowicz JM 2001 Enhanced neurogenesis after transient global ischemia in the dentate gyrus of the rat. Exp Brain Res 136:313-320

18. Zhang RL, Zhang ZG, Zhang L, Chopp M 2001 Proliferation and differentiation of progenitor cells in the cortex and the subventricular zone in the adult rat after focal cerebral ischemia. Neuroscience 105:33-41

19. Zhu DA, Liu SH, Sun HS, Lu YM 2003 Expression of inducible nitric oxide synthase after focal cerebral ischemia stimulates neurogenesis in the adult rodent dentate gyrus. J Neurosci 23:223-229

20. Gage FH 2000 Mammalian neural stem cells. Science 287:1433-1438

21. Hastings NB, Tanapat P, Gould E 2001 Neurogenesis in the adult mammalian brain. Clin Neurosci Res 1:175-182

22. Pencea V, Bingaman KD, Freedman LJ, Luskin MB 2001 Neurogenesis in the subventricular zone and rostral migratory stream of the neonatal and adult primate forebrain. Exp Neurol 172:1-16

23. Seaberg RM, van der Kooy D 2002 Adult rodent neurogenic regions: the ventricula subependyma contains neural stem cells, but the dentate gyrus contains restricted progenitors. J Neurosci 22:1784-1793

24. Magavi SS, Leavitt BR, Macklis JD 2000 Induction of neurogenesis in the neocortex of adult mice. Nature 405:951-955

25. Yamamoto S, Yamamoto N, Kitamura T, Nakamura K, Nakafuku M 2001 Proliferation of parenchymal neural progenitors in response to injury in the adult rat spinal cord. Exp Neurol 172:115-127

26. Grafe MR 1994 Developmental changes in the sensitivity of the neonatal rat brain. Brain Res 653:161-166

27. Yager JY, Thornhill JA 1997 The effect of age on susceptibility to hypoxic-ischemic brain damage. Neurosci Biobehav Rev 21:167-174

28. Li YB, Kaur C, Ling EA 1998 Neuronal degeneration and microglial reaction in the fetal and postnatal rat brain after transient maternal hypoxia. Neurosci Res 32:137148

29. Dell'Anna ME, Calzolari S, Molinari M, Iuvone L, Calimici R 1991 Neonatal anoxia induces transitory hyperactivity, permanent spatial memory deficits and CA1 cell density reduction in developing rats. Behav Brain Res 45:125-134

30. Nyakas C, Buwalda B, Luiten PGM 1996 Hypoxia and brain development. Prog Neurobiol 49:1-51

31. Pulsinelli WA, Brierley JB, Plum F 1982 Temporal profile of neuronal damage in model of transient forebrain ischemia. Ann Neurol 11:491-498

32. Sherwood NM, Timiras PS 1970 A Stereotaxic Atlas of the Developing Rat Brain. University of California Press, Berkeley, CA, p 209

33. Wolvetang EJ, Johnson KL, Krauer K, Ralph SJ, Linnane AW 1994 Mitochondria respiratory chain inhibitors induce apoptosis. FEBS Lett 339:40-44

34. Park DS, Morris EJ, Greene LA, Geller HM 1997 G1/S cell cycle blockers and inhibitors of cyclin-dependent kinases suppress camptothecin-induced neuronal apoptosis. J Neurosci 17:1256-1270

35. Bossenmeyer-Pourié C, Chihab R, Schroeder H, Daval JL 1999 Transient hypoxia may lead to neuronal proliferation in the developing mammalian brain: from apoptosis to cell cycle completion. Neuroscience 91:221-231

36. Grojean S, Lièvre V, Koziel V, Vert P, Daval JL 2001 Bilirubin exerts additional toxic effects in hypoxic cultured neurons from the developing rat brain by the recruitment of glutamate neurotoxicity. Pediatr Res 49:507-513

37. Bossenmeyer-Pourié C, Daval JL 1998 Prevention from hypoxia-induced apoptosis by preconditioning: a mechanistic approach in cultured neurons from fetal rat forebrain. Brain Res Mol Brain Res 58:237-239

38. Wong-Riley MTT 1979 Changes in the visual system of monocularly sutured or enucleated cats demonstrable with cytochrome oxidase histochemistry. Brain Res 171:11-28

39. Strazielle C, Dubois M, Eyer J, Lalonde R 2002 NFH-LacZ transgenic mice: regional brain activity of cytochrome oxidase. Exp Neurol 177:521-530

40. Strazielle C, Krémarik P, Ghersi-Egea JF, Lalonde R 1998 Regional brain variation of cytochrome oxidase activity and motor coordination in Lurcher mutant mice. Exp Brain Res 121:35-45
41. Alling C 1985 Biochemical maturation of the brain and the concept of vulnerable period. In: Rydberg U (ed) Alcohol and the Developing Brain. Raven Press, New York, pp 5-10

42. Morgane PJ, Austin-LaFrance RJ, Bronzino JD, Tonkiss J, Diaz-Cintra S, Cintra L, Kemper T, Galler JR 1993 Prenatal malnutrition and development of the brain. Neurosci Biobehav Rev 17:91-128

43. Clancy B, Darlington RB, Finlay BL 2001 Translating developmental time across mammalian species. Neuroscience 105:7-17

44. Avishai-Eliner S, Brunson KL, Sandman CA, Baram TZ 2002 Stressed-out, or in (utero)? Trends Neurosci 25:518-524

45. MacManus J, Linnik M 1997 Gene expression induced by cerebral ischemia: an apoptotic perspective. J Cereb Blood Flow Metab 17:815-832

46. Chen J, Nagayama T, Jin K, Stetler RA, Zhu RL, Graham SH, Simon RP 1998 Induction of caspase-3-like protease may mediate delayed neuronal death in the hippocampus after transient cerebral ischemia. J Neurosci 18:4914-4928

47. Isenmann S, Stoll G, Schroeter M, Krajewski S, Reed JC, Bahr M 1998 Differential regulation of $\mathrm{Bax}, \mathrm{Bcl}-2$, and $\mathrm{Bcl}-\mathrm{X}$ proteins in focal cortical ischemia in the rat. Brain Pathol 8:49-63

48. Bédard A, Lévesque M, Bernier PJ, Parent A 2002 The rostral migratory stream in adult squirrel monkeys: contribution of new neurons to the olfactory tubercle and involvement of the antiapoptotic protein Bcl-2. Eur J Neurosci 16:1917-1924

49. Wong-Riley MTT 1989 Cytochrome oxidase: an endogenous metabolic marker for neuronal activity. Trends Neurosci 12:94-101

50. Vila M, Levy R, Herrero MT, Ruberg M, Faucheux B, Obeso JA, Agid Y, Hirsch E 1997 Consequences of nigrostriatal denervation on the functioning of the basal ganglia in human and nonhuman primates: an in situ hybridization study of cytochrome oxidase subunit I mRNA. J Neurosci 17:765-773

51. Sokoloff L, Reivich M, Kennedy C, DesRosiers MH, Patlak CS, Pettigrew KD, Sakurada O, Shinohara M 1977 The $\left[{ }^{14} \mathrm{C}\right]$ deoxyglucose method for the measurement of local cerebral glucose utilization: theory, procedure, and normal values in the conscious and anesthetized albino rat. J Neurochem 28:897-916

52. Dimlich RVW, Showers MJ, Shipley MT 1990 Densitometric analysis of cytochrome oxidase in ischemic rat brain. Brain Res 516:181-191

53. Anderson A, Oviedo M, Adcock LM, Yamashita Y, Louis PT, Goddard-Finegold J 1996 Cytochrome oxidase is decreased in piglet hippocampus following hypoxiaischemia. Metab Brain Dis 12:61-68

54. Nakatsuka H, Ohta S, Tanaka J, Toku K, Kumon Y, Maeda N, Sakanaka M, Sakaki S 2000 Histochemical cytochrome $c$ oxidase activity and caspase-3 in gerbil hippocampal CA1 neurons after transient forebrain ischemia. Neurosci Lett 285:127-130

55. Ikonomidou C, Turski L 1996 Neurodegenerative disorders: clues from glutamate and energy metabolism. Crit Rev Neurobiol 10:239-263

56. Dave KR, Saul I, Busto R, Ginsberg MD, Sick TJ, Perez-Pinzon MA 2001 Ischemic preconditioning preserves mitochondrial function after global cerebral ischemia in rat hippocampus. J Cereb Blood Flow Metab 21:1401-1410

57. Alvarez-Buylla A, Garcia-Verdugo JM 2002 Neurogenesis in adult subventricular zone. J Neurosci 22:629-634

58. Rakic P 2002 Neurogenesis in adult primate neocortex: an evaluation of the evidence. Nat Rev Neurosci 3:65-71

59. Levison SW, Rothstein RP, Romanko MJ, Snyder MJ, Meyers RL, Vannucci SJ 2001 Hypoxia/ischemia depletes the rat perinatal subventricular zone of oligodendrocyte progenitors and neural stem cells. Dev Neurosci 23:234-247

60. Levison SW, Romanko MJ, Rothstein RP, Snyder MJ 2003 Recruitment of neural stem cells following perinatal hypoxic/ischemic insult. J Neurochem 85(suppl 1):3

61. Kishi K 1987 Golgi studies on the development of granule cells of the rat olfactory bulb with reference to migration in the sub-ependymal layer. J Comp Neurol 258:112-124

62. Luskin MB 1993 Restricted proliferation and migration of postnatally generated neurons derived from the forebrain subventricular zone. Neuron 11:173-189

63. Schmidt W, Reymann KG 2002 Proliferating cells differentiate into neurons in the hippocampal CA1 region of gerbils after global cerebral ischemia. Neurosci Lett 334:153-156

64. Arvidsson A, Collin T, Kirik D, Kokaia Z, Lindvall O 2002 Neuronal replacement from endogenous precursors in the adult brain after stroke. Nat Med 8:963-970

65. Nakatomi H, Kuriu T, Okabe S, Yamamoto S, Hatano O, Kawahara N, Tamura A, Kirino T, Nakafuku M 2002 Regeneration of hippocampal pyramidal neurons after ischemic brain injury by recruitment of endogenous neural progenitors. Cell 110:429-441

66. van Praag H, Schinder AF, Christie BR, Toni N, Palmer TD, Gage FH 2002 Functional neurogenesis in the adult hippocampus. Nature 415:1030-1034

67. Kokaia Z, Lindvall O 2003 Neurogenesis after ischaemic brain insults. Curr Opin Neurobiol 13:127-132 